\title{
Control of the Local Scouring Around the Cylindrical Bridge Pier Using Armed Soil by Geotextile
}

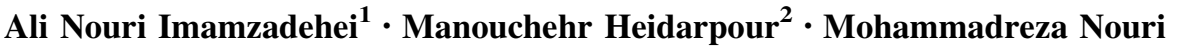 \\ Imamzadehei $^{3} \cdot$ Behzad Ghorbani $^{3} \cdot$ Amirhamzeh Haghiabi $^{1}$
}

Received: 9 September 2015/Accepted: 20 January 2016/Published online: 1 February 2016

(C) Springer International Publishing Switzerland 2016

\begin{abstract}
Flood currents are considered threatening factors by creating local scour along bridge piers. One method for decreasing local scour is to strengthen the bed against imposed tensions. Among methods which can be appropriate in decreasing and controlling local scour of bridge piers directly is to put riprap beside bridge piers and to employ geotextile around them. Geotextiles form a large group of geosynthetic products produced from polypropylene and polyester fibers, and are used in separation, strengthening and reinforcing, filtration, and drainage. In the present study, the effect of geotextile layer in decreasing local scour of cylindrical single-pier was investigated and the best coverage pattern with the most effect was obtained so that layers with circular and oval shapes were put around the pier relative to its diameter, and the performance of each was compared with the unprotected pier. Test results showed by using geotextile with an appropriate cover, the scour location is transferred to downstream and the scour depth is decreased. These advantages can reduce the risk of pier failure when the duration of flood is short. The results indicate that the scour reduction increases as the layer area increased. In this case
\end{abstract}

Ali Nouri Imamzadehei

a_noori110@yahoo.com

Manouchehr Heidarpour

heidar@cc.iut.ac.ir

1 Department of Water Engineering, Lorestan University, Khorramabad, Iran

2 Department of Water Engineering, Isfahan University of Technology, Isfahan, Iran

3 Department of Water Engineering, Shahrekord University, Shahrekord, Iran the oval layer has a better efficiency compared to the circular one.

Keywords Local scour · Bridge pier - Geotextile . Coverage pattern

$\begin{array}{ll}\text { List } & \text { of Symbols } \\ y & \text { Flow depth } \\ u & \text { Velocity } \\ u_{c}^{*} & \text { Critical shear velocity } \\ u_{\mathrm{c}} & \text { Critical velocity } \\ \sigma_{\mathrm{g}} & \text { Geometric standard deviation } \\ d_{50} & \text { Mean particle size } \\ D & \text { Pier diameter } \\ d_{\mathrm{s}} & \text { Scour depth } \\ d_{\mathrm{se}} & \text { Equilibrium scour depth } \\ t & \text { Time } \\ t_{\mathrm{e}} & \text { Equilibrium time }\end{array}$

\section{Introduction}

Bridge scour is one of the main causes of bridge failures. Scour is a natural phenomenon caused by erosion or removal of stream bed or bank material from bridge foundations due to flowing water. Bridge scour is a dynamic phenomenon that varies with many factors such as water depth, flow angle and strength, pier and abutment shape and width, material properties of the sediment, and so on. This phenomenon is created locally as a result of mutual effect of water stream geometry, bed and current specifications around the pier.

The interaction between a water stream and a bridge pier in mobile-bed rivers produces a complex three-dimensional 
flow field [1]. A strong pressure gradient occurs upstream to the pier, and the downward negative stagnation pressure gradient generates a down flow. The approaching flow curves down into the scour hole, forming a horseshoe vortex. In addition, the water surface rises upstream of the pier, forming an emerging circular profile, known as "bow wave". The lateral deviation of the flow around the pier generates a shedding wake vortex system. The combined action of horseshoe and wake vortexes causes the development of local scouring [2].

Different countermeasures have been tested and proposed in the literature in order to reduce the local scour hole dimensions. One direct method of decreasing and controlling local scour of the bridge piers is to strengthen the pier by riprapping around the pier. Chiew and Lim [3], focused on using armoring materials for reducing local scour at bridge piers. Efforts have been made to reduce scour by using submerged vanes, a delta-wing-like fin in front of the pier [4], and slot through the pier [5, 6].

Geotextiles, which are produced from polypropylene and polyester fibers, form a large group of geosynthetic products, and are on the market in woven and non-woven groups from the point of commercial structure. A great number of studies have been conducted in order to use geotextile in applications such as strengthening and reinforcing the retaining walls [7], drainage in water transfer canals [8], and dams [9]. In erosion control, the geotextile protects soil surfaces from the tractive forces of moving water and rainfall erosion. Geotextiles can be used in ditch linings to protect erodible fine sands or cohesionless silts. The geotextile is placed in the ditch and is secured in place by stakes or is covered with rock or gravel to secure the geotextile, and dissipate the energy of the flowing water. It seems that this material can be used to strengthen river beds adjacent to bridge piers and to control the scour around them concurrently playing the role of riprap and collar. Up to now, the effects of geotextile armored soil on scour-reduction is not investigated. The primary objective in the present study is to determine if geotextile has an acceptable effect on scour-reduction in bridge pier. The second objective is to investigate in selecting the best dimensions of cover in order to minimize the scour phenomenon.

\section{Materials and Methods}

The experiments were carried out in a $20 \mathrm{~m}$ long, $0.60 \mathrm{~m}$ wide, and $0.60 \mathrm{~m}$ deep, Plexiglass-sided flume. The section in which piers were located, was $3 \mathrm{~m}$ long and was situated $10 \mathrm{~m}$ from the entrance of the flume in order to fully developed flow. Uniform sediment with the mean particle sizes of $0.82 \mathrm{~mm}$ and geometric standard deviation of particles $\sigma_{\mathrm{g}}$ equal to 1.13 filled a recess in which piers located. According to Chiew and Melville [10], when geometric standard deviation of particles are lower than 1.3 , the effect of non-uniformity sediment on the depth of scour hole becomes negligible. The water depth in the flume was adjusted by a sluice gate at the downstream end of the flume.

Pier modeled by cylindrical Perspex pipes with diameter of $50 \mathrm{~mm}$. According to Chiew and Melville [10], the pier diameter should not be more than $10 \%$ of channel width so that the effect of flume sidewalls on the depth of scour hole becomes negligible. Since the pier diameter to mean particle size $\left(D / d_{50}\right)$ was more than $20-25\left(D / d_{50}=61.7\right)$, the effect of sediment size on the depth of scour hole becomes negligible [11]. The geotextile layer was installed around pier and seamed to soil by a wireframe under the layer and special nails. Figure 1 shows the pier model installation in the flume.
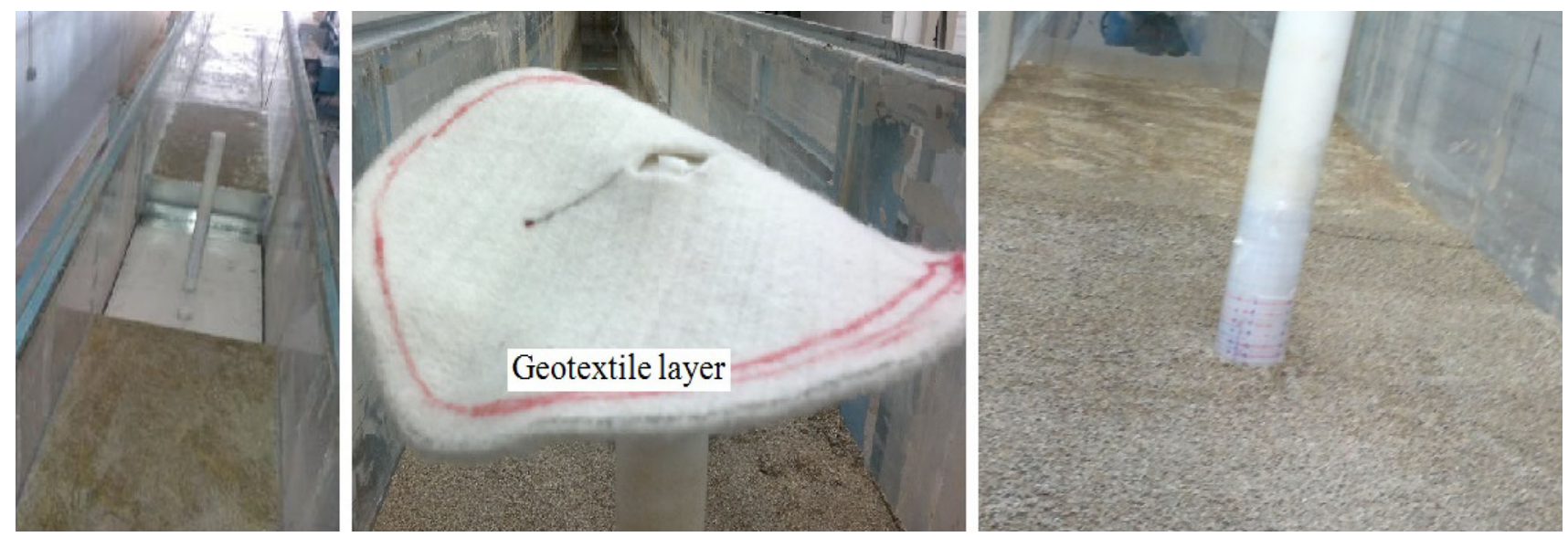

Fig. 1 Pier model installation in the flume 
Table 1 Summarized of test conditions

\begin{tabular}{lllllll}
\hline Fr & $u / u_{\mathrm{c}}$ & $u_{\mathrm{c}}^{*}(\mathrm{~m} / \mathrm{s})$ & $u_{\mathrm{c}}(\mathrm{m} / \mathrm{s})$ & $y(\mathrm{~m})$ & $D / d_{50}$ & $d_{50}(\mathrm{~mm})$ \\
\hline 0.187 & 0.93 & 0.0195 & 0.346 & 0.29 & 61.7 & 0.81 \\
\hline
\end{tabular}

Since the maximum depth of scour occurs at the threshold of bed material motion, all the tests were conducted at this condition [12]. The threshold of bed material motion was found by experiment when the pier was not installed. Threshold of material motion was defined as a condition such that although finer bed materials move, the overall average elevation of the bed is not lowered more than 2-3 mm during the period of the experiment. Three velocity profiles were measured by Acoustic Doppler Velocimeter (ADV) in test section of the channel to obtain the flow intensity. These tests showed that with a flow depth of $0.29 \mathrm{~m}$ and a flow rate of $55 \mathrm{l} / \mathrm{s}$, the bed material would be at incipient motion condition. The ratio of shear velocity in these experiments to the critical shear velocity calculated from Shields' diagram was about $0.346 \mathrm{~m} / \mathrm{s}$. The test conditions are summarized in Table 1.

The reinforced plates used (geotextiles) in the tests of this research consisted of oval shaped plates in various sizes with a proportion of the pier diameter covering in various, and were used along evidence treatment (without coverage) to determine the best cover. The sizes of these plates were tested on studies carried out on ripraps and their suggested patterns [4, 13, 14], on Fig. 2, and then, the most appropriate pattern was obtained on the bass of the amount of scour.

The physical and mechanical specifications of the material in geotextile plates have been mentioned in Table 2.

Definition of scour equilibrium time plays an important role in the results obtained. Scour equilibrium time defined the equilibrium to occur when the scour depth does not change appreciably with time [15]. Assuming that equilibrium scour exists but that it is not reached in a finite time. Several researchers have come up with different definitions of time to equilibrium scour depth. Based on timescale studies on local scour, Melville and Chiew [16] concluded that $50-80 \%$ of the equilibrium scour depth develops at a stage after $10 \%$ of equilibrium time, depending on the approach flow velocity. Therefore, determination of scour depth development corresponding to a peak flood flow and time-to-peak of flood hydrograph is important. For a single pier, Ettema [17] defined the scour equilibrium time when the scour depth did not change by more than $1 \mathrm{~mm}$ over a period of $4 \mathrm{~h}$. Also Melville and Chiew [16] defined the equilibrium time when the scour depth did not change by more than $5 \%$ of the pier diameter over a period of $24 \mathrm{~h}$. Melville and Chiew [16] developed Eq. 1 for predicting the time to reach the clear-water equilibrium scour depth.

$\frac{d_{\mathrm{s}}}{d_{\mathrm{se}}}=\exp \left\{-0.03\left|\frac{u}{u_{\mathrm{c}}} \ln \frac{t}{t_{\mathrm{e}}}\right|^{\frac{1}{6}}\right\}$

In which $d_{\mathrm{s}}$ is the scour depth, $u$ is the velocity, $u_{\mathrm{c}}$ is the critical velocity, and $t$ is the time.

Figure 3 shows comparison of experimental values of $d_{\mathrm{s}} / D$ and computed value from Eq. 1 . It can be seen from the figure that depth of scour increases with time and there is a good agreement between experimental data and results obtained from Eq. 1 in $56 \mathrm{~h}$. It was found that $56 \mathrm{~h}$ was necessary for reaching equilibrium scour depth, and observed that $90 \%$ equilibrium scour depth occurs in $20 \mathrm{~h}$ ( $1 / 3$ of rudimentary test time).

\section{Results and Discussion}

\section{The Test Without Geotextile Layer}

In the test without geotextile layer, the pier was put in the current route without installing the pier and the intended discharge and depth easily occurred in the flume. It was

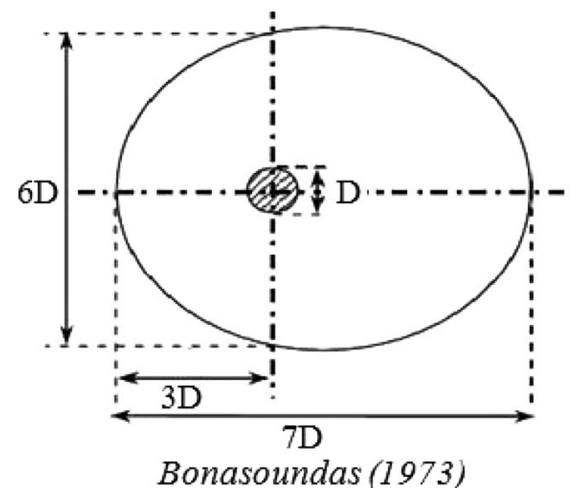

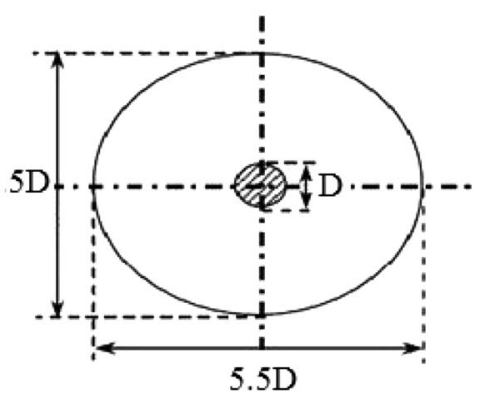

Gales (1938)

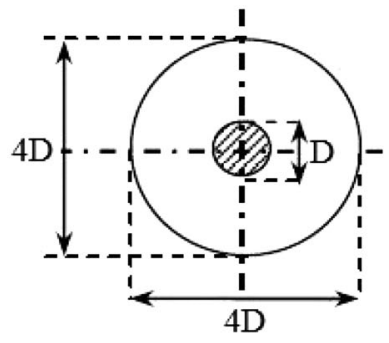

Neil (1973)

Fig. 2 Initial patterns for the geotextile cover size 
Table 2 Physical and mechanical specifications of geotextile layers

\begin{tabular}{llll}
\hline Specifications & Unit & Test method & Quantity \\
\hline Mass in surface unit & $\mathrm{g} / \mathrm{m}^{2}$ & DIN EN 29073.1 & 400 \\
Thickness & $\mathrm{mm}$ & DIN EN 29073.2 & 4 \\
Maximum tension in length and width & $\mathrm{kN}$ & DIN EN 29073.3 & 26 \\
Hole resistance CBR & $\mathrm{kN} / \mathrm{m}$ & DIN EN ISO12236 & 4.1 \\
Vertical water penetrability & $\mathrm{m} / \mathrm{sec} 10^{-3}$ & DIN EN ISO11058 & 2.4 \\
Expansion force and tension in length and width & $\mathrm{N}$ & ASTM D 4632 & 1380 \\
Trapezoid rupture strength in length and width & $\mathrm{N}$ & ASTM D 4533 & 510 \\
Compression and resistance index & $\mathrm{N}$ & ASTM D 4833 & 720 \\
\hline
\end{tabular}

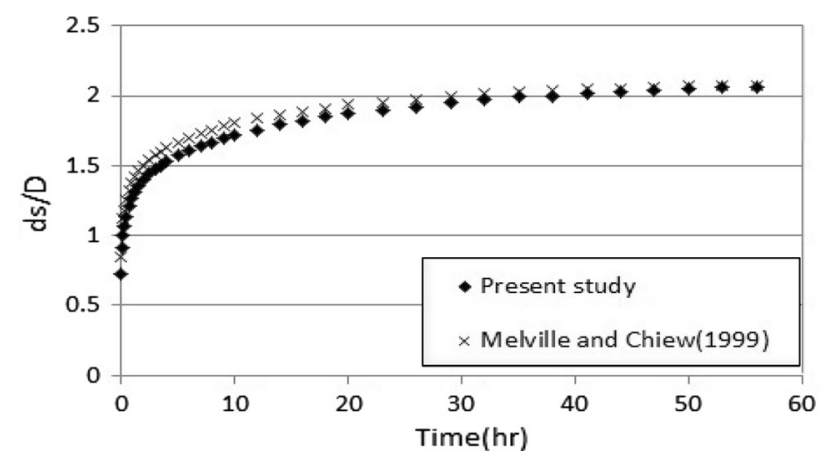

Fig. 3 Comparison of experimental values of $d_{\mathrm{s}}$ with computed value from Melville and Chiew equation

noticed that by creating a horseshoe vortex, the materials in front of the pier are washed forming a pile of both sides of it which gradually moves downstream. Upon reaching the piles to the end of the pier, the protruded vortex is accelerated causing the deepening of the scour hole, and as a result, the fall of its walls. Hence, the scour speed is high in the beginning of the test but gradually diminishes. Temporal development of the scour hole and the scour hole dimensions in this test are seen in Fig. 4. As seen in this figure, a change in scour depth after $8 \mathrm{~h}$ is very small. Also, maximum scour depth in the front of the pier was $11.9 \mathrm{~cm}$ which approximately 2.6 times as much as the pier diameter. Ghorbani and kells [18] deduced that more than $70 \%$ of scour occurs in the first $7 \mathrm{~h}$ of the test. In this case more than $75 \%$ of the scour occurs in the first $8 \mathrm{~h}$. Comparison of the results of the present study with the results of them shows good agreement.

\section{The Test with Geotextile Layer}

As the first treatment of geotextile layer to the size presented by Bonasondas [13] for the riprap cover (Fig. 1). The pier surrounding was laid on the soil surface so that $2 \mathrm{~mm}$ of soil covered its surface. After $12.5 \mathrm{~h}$ at the lowermost of the layer, scour started with a very slow speed with a development in length, width and depth downstream, and advanced upwards at the point of contact between the layer and the soil on the sides. The speed of scouring progress was so slow that after $56 \mathrm{~h}$, the hole depth at its deepest point reached $6 \mathrm{~cm}$, and the amount of scour in the area where the layer has been laid on the surface equals zero. Figure 5 shows the hole dug and time development in this case.

In order to determine the effect of the depth of geotextile layer insertion, a layer of the same size was laid in the depth of $0.8 D$ of soil surface. It was observed that the scour up to the layer surface continues like when there is no layer. By effect of horseshoe vortex, the scour expanded in length and width in the first $2 \mathrm{~min}$ in downstream. Also the scour depth advanced up to the layer surface in the front and sides of the pier. While behind the pier, due to the wake vortex, this process lasted 42 min. Figure 6 shows dimensions of scour hole (Fig. 6a) and the graph comparing the development of scour between this case and the evidence test (Fig. 6b).

In order to understand the effect of geotextile layer shape, with regard to Gales suggested pattern [4], the layer shape was inclined from oval to circular and was laid on the soil surface. In this state, too, the layer on the soil surface was covered with $2 \mathrm{~mm}$ of soil. After $8.5 \mathrm{~h}$, the first signs of layer leaching appeared. It was progressing upstream longitudinally and towards the pier widthwise at a very low speed so that at the end of the test $(56 \mathrm{~h})$ the amount of scour under the layer was merely $2.5 \mathrm{~cm}$. At the lowermost part of the layer, a hole was formed which was larger than the oval cover state (Bonasondas) from all aspects and its depth reached $8 \mathrm{~cm}$ at the deepest point. Figure 7 shows the layer and formed hole (Fig. 7a) and time development of scouringin this state (Fig. 7b).

The test process for Gales Pattern in the depth, when the layer lay at a depth of $0.8 D$, was similar to that with Bonasoundas pattern. The only difference was that in this state, the length of the dug hole showed an increase of about $6 \mathrm{~cm}$ in length and about $4 \mathrm{~cm}$ in width.

By putting the circular layer with Neil's pattern under the previous conditions [14]. It was noticed that two grooves were also gradually developed at the downstream 

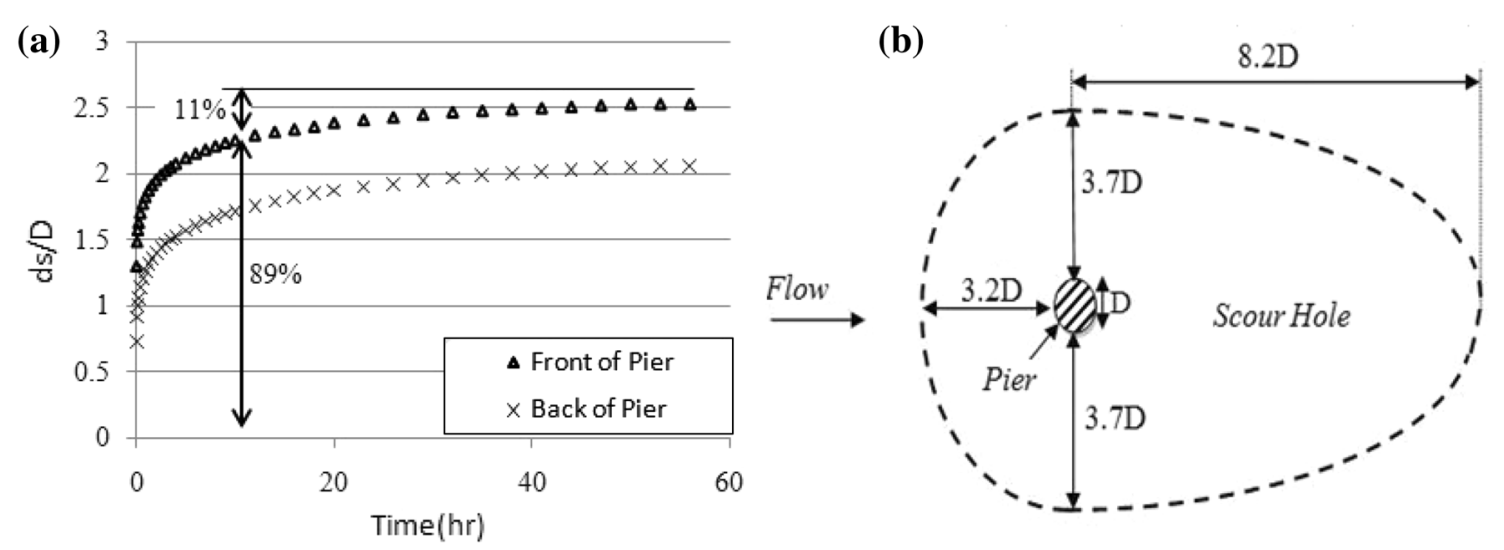

Fig. 4 a Time development of scouring and $\mathbf{b}$ final holes formed
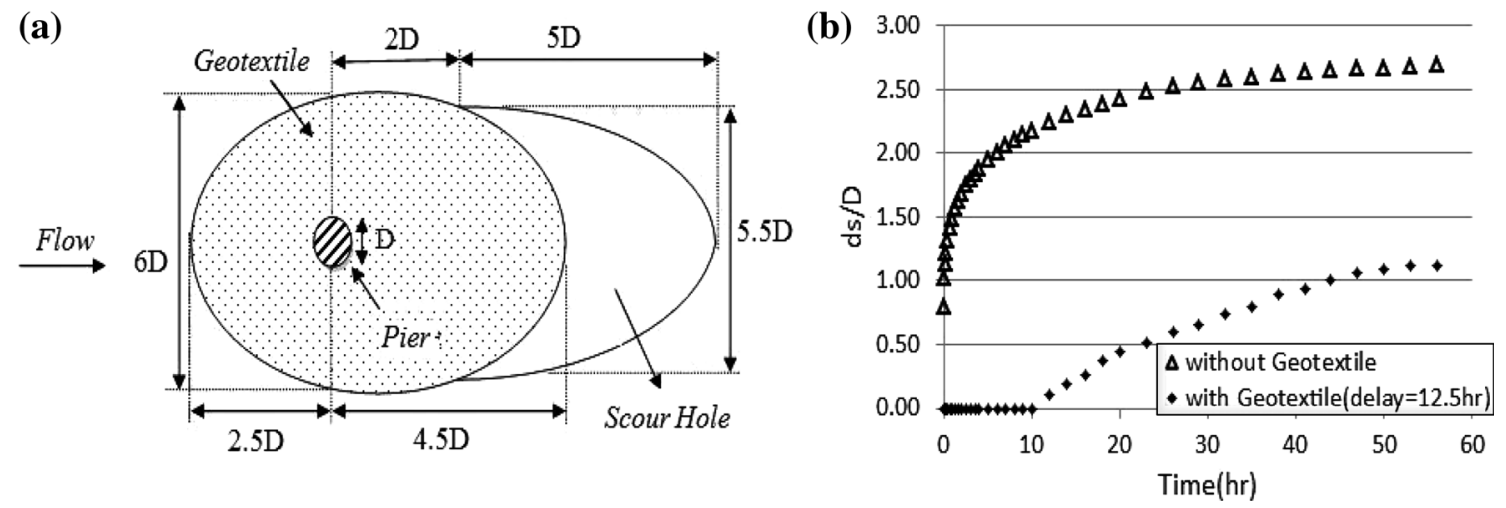

Fig. 5 a Dimensions of hole dug in the pattern suggested by Bonasondas and $\mathbf{b}$ time development of scouring
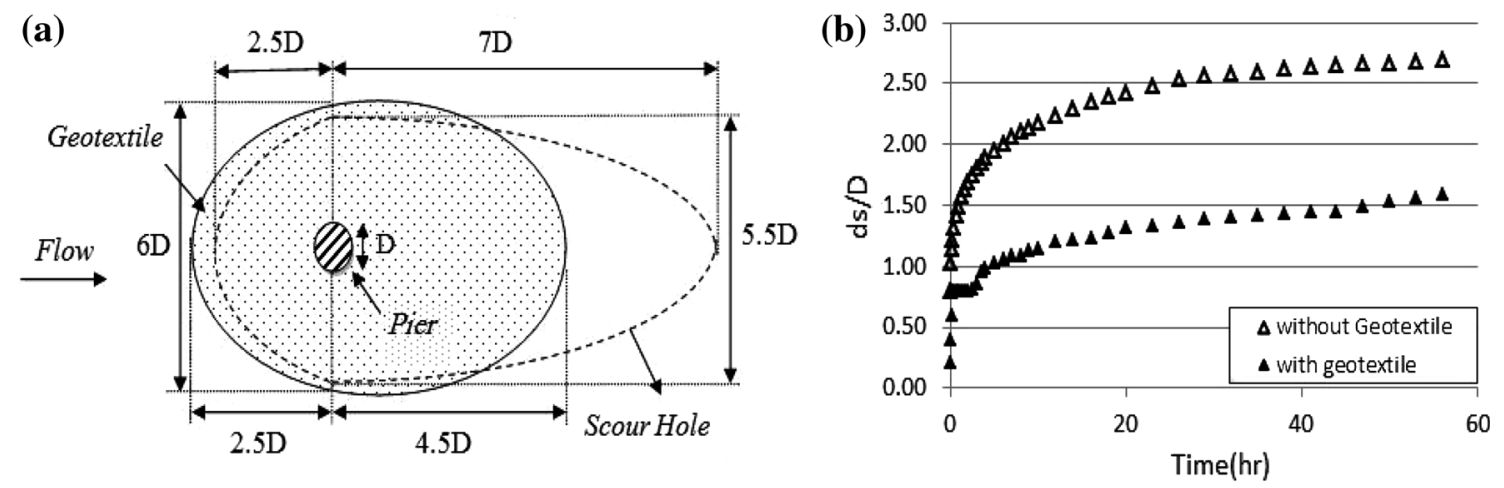

Fig. 6 a Dimensions of the hole formed and $\mathbf{b}$ graph of final scour depth with and without a geotextile layer

rim of the layer. After $2 \mathrm{~h}$ the grooves gradually developed and extended upstream and eventually reached at upstream edge. At this moment, the flow was intensified through the groove, reducing the side slope of the groove and with sediment removal from the grooves the scour hole extended upstream of the pier and below the layer. With developments in the depth of the hole and evacuation beneath the geotextile layer, due to their flexibility, the edges of the layer are bent downwards and the speed of digging the hole is decreased. Figure 8 shows a comparative state of scour between this state and the evidence test.

\section{Appropriate Coverage Pattern}

With regard to the scour process in the above pattern, the cover behind the pier should be increased approximating the shape to an oval as much as possible. Hence, a cover was presented to Fig. 9. By putting a layer with these 
(a)

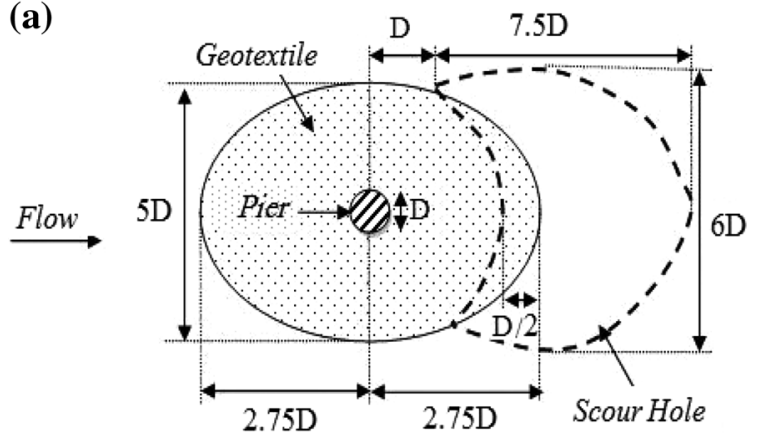

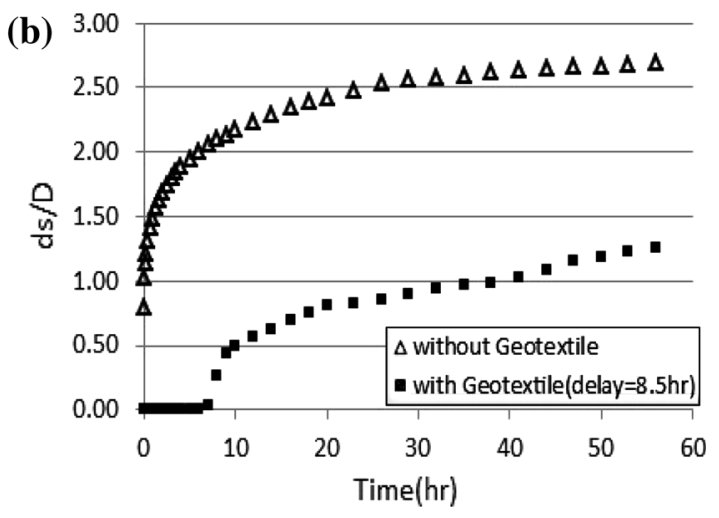

Fig. 7 a schema of hole dimensions dug for a layer with Gales's pattern and b time development of scouring
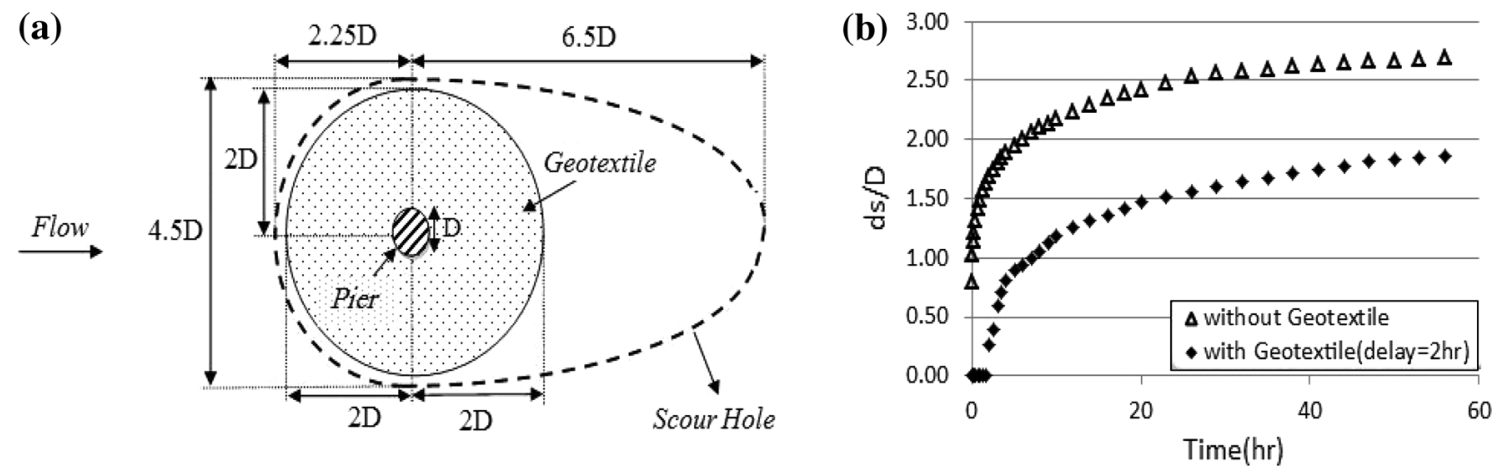

Fig. 8 a The scour hole in the circular layer application in Neil's pattern and b time development of scouring

(a)

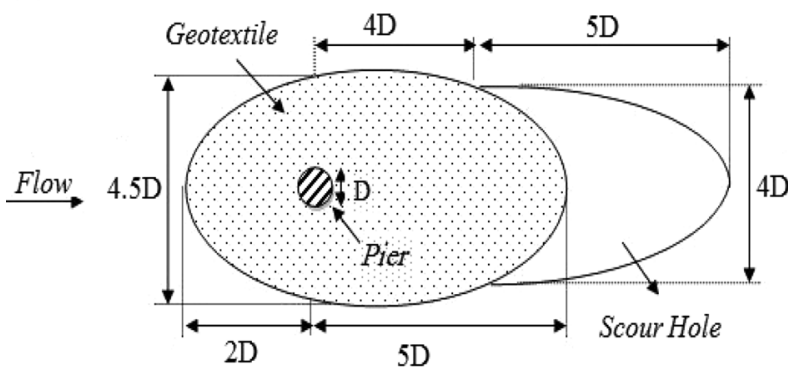

(b)

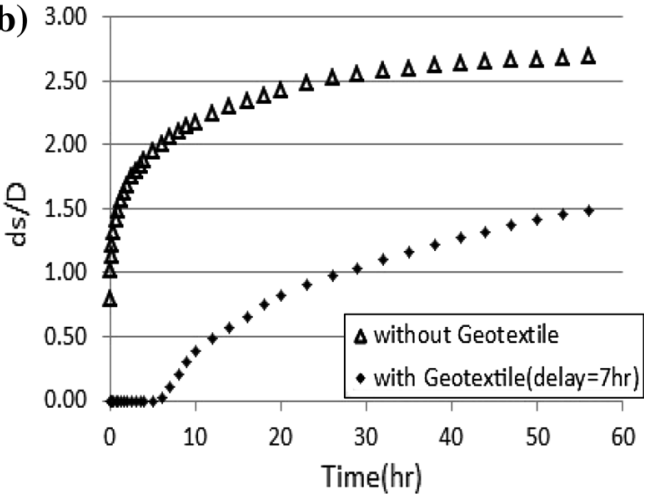

Fig. 9 a The dimensions of the suggested layer and the final amount of scour with it and $\mathbf{b}$ time development of scouring

dimensions, after $7 \mathrm{~h}$, the first signs of scour were noticed down the layer developing at a very low speed. Only a hole was formed at the downstream edges of the layer whose depth reached $7.4 \mathrm{~cm}$ at its deepest point. All during the test no scour occurred in the front and at the sides of the pier. The layer shape, final dimensions of the hole and time development of scouring can be seen in Fig. 9.

In order to decrease the depth and dimensions of the hole in this state, because in the above pattern the scour area was less than the geotextile limit in the sides and the front of the pier, a layer was used whose width was less than the previous state but its cover area behind the pier was more.

With trial and error, finally the layer presented in Fig. 10 was chosen. In this state after $19 \mathrm{~h}$ the first signs of scour in downstream edges are noticed. The end of the test depth of scour hole was about $3.3 \mathrm{~cm}$. The layer shape, final dimensions of the hole and time development of scouring can be seen in Fig. 10. With regard to negligible amount of scour, this arrangement is suggested as the best pattern in 

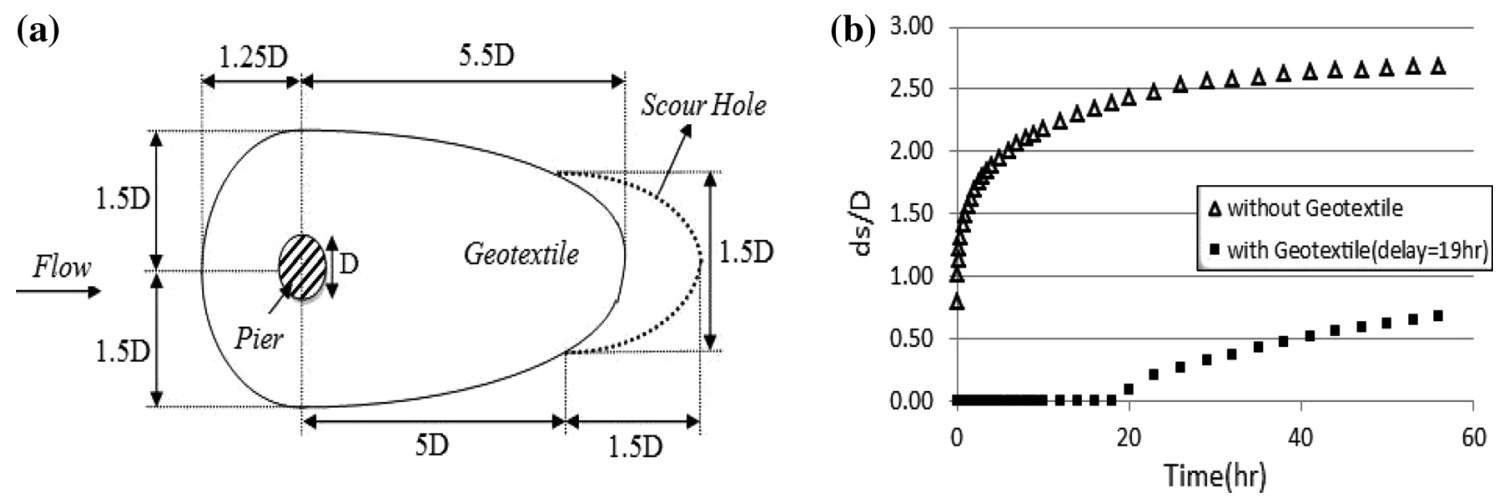

Fig. 10 a The most appropriate dimensions of geotextile layer and the final amount of scour with it and $\mathbf{b}$ time development of scouring

Fig. 11 Time development of scouring in all of patterns

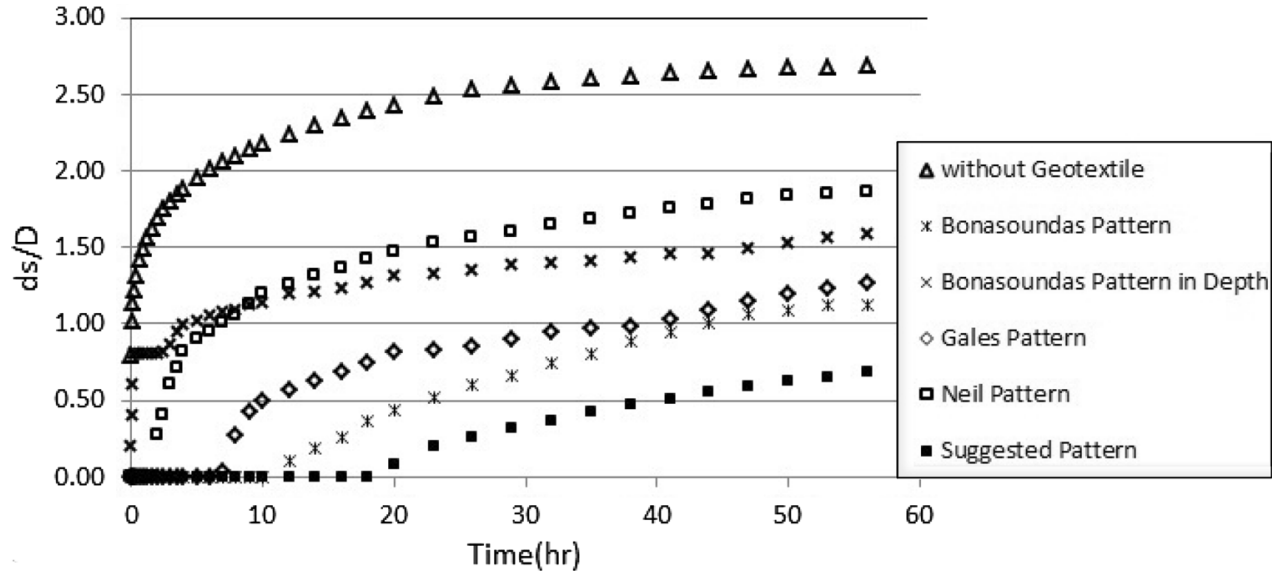

geotextile installation. As far as economy and method of application are concerned, the larger layer; and as far as the scour is concerned, the smaller layer would be problematic. It is worth mentioning that this pattern is close to the one suggested by Heidarpoor et al. [19] in determining the most appropriate riprap cover pattern.

In Fig. 11, time development of scouring in all of patterns that used can be seen. The Maximum scour depth in upstream of the protected pier was $7.9 \mathrm{~cm}$ for Gales pattern. The efficiency of the best pattern that has been shown in Fig. 10a is more than Gales pattern, nevertheless with geotextile in this pattern, scouring was more postponed.

\section{Conclusion}

In this study, an investigation of the reduction of scour around circular bridge piers using geotextile has been carried out for the case of clear-water flow over uniform sediment. Ten long-lasting experiments have been used to assess appropriate cover. The pattern that be seen in Fig. 10 is suggested as the best pattern in geotextile installation. By using geotextile with the appropriate cover, the scour location is transferred to downstream and the scour depth is decreased. Geotextile has a dual performance in decreasing scour; that is, it both strengthens the bed against the current and changes the flow pattern. Due to the intensity of the protruding vortexes behind the pier, the circular pattern is not suitable for the coverage. The circular layer of geotextile has an application similar to the collar, and a comparison of its performance is suggested for further studies.

\section{References}

1. Dey S, Raikar RV (2007) Characteristics of horseshoe vortex indeveloping scour holes at piers. Hydraul Eng J 133(4):399-413

2. Raudkivi AJ (1998) Loose boundary hydraulics. A.A. Balkema, Rotterdam

3. Chiew YM, Lim S (2003) Protection of bridge piers using a sacrificial sill. Water Marit Eng J 156(1):53-62

4. Gales RR (1938) The principles of river-training for railway bridges, and their application to the case of the Harding Bridge over the Lower Ganges at Sara. Inst Civil Eng J Lond Engl 10(2):136-224

5. Chiew YM (1992) Scour protection at bridge piers. Hydraul Eng J 118(11):1260-1269 
6. Kummar V, RangaRaju KG, Vittal N (1999) Reduction of local scour around bridge piers using slot and collar. Hydraul Eng $\mathrm{J}$ 125(12):1302-1305

7. Noorzad R, Mirmoradi SH (2010) Laboratory evaluation of the behavior of a geotextile reinforced clay. Geotext Geomembr J 28(4):386-392

8. Hornsey WP, Carley JT, Coghlan RJ (2011) Geotextile sand container shoreline protection systems: design and application. Geotext Geomembr J 29(4):425-439

9. Hari SM, Noorzad R, Oskoorouchi AM (2000) Effect of geotextile reinforcement on the mechanical behavior of sand. Geotext Geomembr J 18(6):385-402

10. Chiew YM, Melville BW (1987) Local scour around bridge piers. Hydraul Res J 25(1):15-26

11. Raudkivi AJ, Ettema R (1983) Clear water scour at cylindrical piers. Hydraul Eng J 109(3):338-350

12. Raudkivi AJ (1990) Loose boundary hydraulics, 3rd edn. Pergamon, Oxford
13. Bonasoundas M (1973). Stromungsvorgang und kolkproblem. Rep No. 28, Oscar von Miller Institut Tech, University of Munich, Germany

14. Neil CR (1973). Guide to bridge hydraulics. Road and Transportation Association of Canada, University of Toronto, Canada

15. Chabert J, Engeldinger P (1956) Etude des affonillements author des piles des ponts. Laboratoire National d'Hydraulique, Chatou (in French)

16. Melville BW, Chiew YM (1999) Time scale for local scour at bridge piers. Hydraul Eng J 125(1):59-65

17. Ettema R (1980). Scour at bridge piers. Rep No. 112, Department of Civil Engineering, University of Auckland, Auckland, New Zealand

18. Ghorbani B, Kells JA (2008) Effect of submerged vanes on the scour occurring at a cylindrical pier. Hydraul Res J 46(5):610-619

19. Heidarpour M, Keykhaei M, Mousavi SF (2008) A study of coverage pattern of riprap around the bridge pier group. Iran Agric J 49(2):13-29 